\title{
Wear Performance of Thermally Sprayed NiCrBSi and NiCrBSi-WC Coatings Under Two Different Wear Modes
}

\author{
R. Rachidi ${ }^{{ }^{*}}$, B. El Kihel ${ }^{1}$, F. Delaunois ${ }^{2}$, V. Vitry ${ }^{2}$, D. Deschuyteneer ${ }^{3}$ \\ ${ }^{1}$ Equipe de Génie Industriel, Maintenance et Production Mécanique, Ecole Nationale des Sciences Appliquées, University \\ Mohammed Premier, Oujda, Morocco \\ ${ }^{2}$ Service de Métallurgie, Faculté Polytechnique, UMONS, Mons, Belgium \\ ${ }^{3}$ Belgian Ceramic Research Centre, Mons, Belgium
}

\section{Received 29 Aug 2016 \\ Revised 01 Oct 2016, \\ Accepted 04 Oct 2016 \\ Keywords

$$
\begin{aligned}
& \checkmark \text { NiCrBSi } \\
& \checkmark \text { MMC materials, } \\
& \checkmark \text { Wear resistance, } \\
& \checkmark \text { Coatings, } \\
& \checkmark \text { Microstructure, } \\
& \checkmark \text { Hardness, } \\
& \checkmark \text { WC particles }
\end{aligned}
$$

r.rachidi1988@gmail.com Phone: (+212)622313875

\begin{abstract}
$\mathrm{NiCrBSi}$ is a Ni-based alloy universally recognized for its superior mechanical properties, attributed to the presence of hard-dispersed carbides and borides, which is dependent on the deposition technique. Moreover, Metal Matrix Composites (MMC) materials will aim to combine the resilience of metals with high wear resistance specific of ceramics which made them innovative for a large wide of wear resistance applications. In this paper, thick $\mathrm{NiCrBSi}$ and NiCrBSi-WC coatings are made ontoS235JR mild steel substrates using an oxyacetylene flame-spraying torch (SuperJetEutalloy, Castolin Eutectic). Two different wear tests: sand/wheel wear test in dry conditions and the pin-on-disc wear test in continuous motion are used to investigate addition effects of WC reinforcing ceramic phase on the microstructure and wear resistance of the coatings layers. The results show that the presence of ceramic phase affects the wear resistance of the coating. For both wear tests, the metallic alloy coating has an improved wear resistance than the reinforced ones. WC reinforcement does not play the protective role of the matrix against wear but improve the hardness. Wear mechanism is mainly controlled by the scratching and by the pull out of WC particles because of their faceted shape.
\end{abstract}

\section{Introduction}

Thermal spraying is one of the most widely used techniques of surface treatment against wear and corrosion. Especially, flame spraying process due to its advantages, such as its being more economical, easier to implement and more adaptable to a wide range of materials. However, mechanical performances are not always satisfactory because of high porosity, cracks and weaker adhesion. To obtain hard wear and corrosion-resistant coatings, the most suitable materials are those like Nickel, Cobalt-based alloys, hardmetals and ceramics [1-3]. Because of their high melting points, ceramics are depositedin preference by plasma spraying technique, while the conventional flame and HVOF spraying techniques are used to deposit metals and hard metals materials. For many applications, Ni-based alloy is used to improve the performances of components whose surface is subjected to wear and/or corrosion. It can be also used to replace hard chrome coating which endangering human health and environment [4]. Many studies are reported on tribological properties of Ni-based coatings produced by thermal spray and laser cladding techniques [5-9]. Ni-based alloy with an amount of hard ceramic phase is reported as more advantageous than the metal material deposited alone. Tungsten carbide (WC) and chromium carbide $\mathrm{Cr}_{3} \mathrm{C}_{2}$ [10] are the most commonly recommended phase reinforcement. Wear resistance is enhanced by Ni-based alloy and reinforced Ni-based alloy produced by thermal spraying process.

To quantify the wear of coating, it is necessary to perform tests under conditions similar to those of the operative regime, but laboratory tests are commonly used as a quantitative tool to describe the wear behaviour of the material tested [11]. For this, a large number of tribological tests are available. The results of tribotest are strongly related not only to the characteristics of the materials couple, but also to the whole mechanical system and its environment. Consequently, selecting the most appropriate test for a specific objective is fundamental to making meaningful interpretations. Several studies have already exposed the tribological behaviour of the Nibased and composite coatings under different conditions, such as dry sliding [4, 7, 12-14], slurry erosion [15], liquid impingement erosion [16], solid-particle erosion [17] and others. In fact, in several cases, composite 
coatings offer the best wear performances, thanks to the hardness conferred by carbide particles and to the toughness provided by the metal matrix. Weighing and measurement of changes in dimensions are the most commonly used techniques to evaluate wear. Weighing may often be difficult if the worn volumes are small compared to the weight of the component. To determine the wear mechanism, which caused the surface damage, the study of worn surfaces with microscopy or surface topography techniques becomes an integral part of the evaluation of coatings.

The aim of the present work is to verify if the addition of hard ceramic particles can effectively improve the dry sliding performance of NiCrBSi coatings produced using a commercially available materials. Two wear tests namely the dry sand/wheel erosive wear test and the pin-on-disc abrasive wear test in continuous motion, have been carried out on two different flame sprayed coating deposited on mild steel substrate: NiCrBSi alloy and the same material reinforces with WC hard particles. After the wear tests, the wear resistance was investigated. Furthermore, the worn surfaces were characterized using digital microscope and Scanning Electron Microscope (SEM) and by energy dispersive X-rays spectrometry (EDS) to determine the main mechanism responsible for wear behaviour.

\section{Experiments}

\subsection{Test materials and procedure}

Two commercially powders used as feedstock material were identified from Castolin Eutectic Company. The first powder is Ni-based alloy powder, designated Borotec 10009, with spherical morphology, hardness of 58 HRC and nominal chemical composition: $\mathrm{Cr} 14,8 \%$, B 3,1\%, Si 4,3\%, Fe 3,7\%, C 0,75\%, and Ni balance. A second powder consisting of a mixture of NiCrBSi matrix with $60 \%$-wt. of WC designated Eutalloy 10112 with a non-spherical angular morphology and hardness of $63 \mathrm{HRC}$. This latest has nominal chemical composition: WC 60\%, Cr 7,3\%, B 3,3\%, Si 4,5\%, Fe 6,3\%, C 0,25\% max, and Ni balance. Mild steel S235JR was used as substrate and the nominal chemical composition is: $\mathrm{C} 0.17 \%$ max., S $0.045 \%$ max., Mn $1.40 \%$ max., P $0.045 \%$ max., $\mathrm{N} 0.009 \%$ max. and Fe balance. Before the coating process, specimens are manufactured from mild steel S235JR bars that were cut and then machined into discs with $50 \mathrm{~mm}$ in diameter and $10 \mathrm{~mm}$ in thickness. Then, specimen's surface was rectified to create roughness profile to the surface. Deposition process was performed with oxyacetylene flame thermal spraying technique using SuperJetEutalloy (SuperJetEutalloy, Castolin Eutectic) torch. A group of samples was coated with NiCrBSi powder alloy and another group with reinforced NiCrBSi-WC powder. By means of Scanning Electron Microscopy (SEM), the basic elements of studied layers namely $\mathrm{Ni}, \mathrm{Cr}, \mathrm{Si}, \mathrm{C}, \mathrm{W}$ and $\mathrm{Fe}$ were detected. However, due to the detection sensitivity limit, the weight percentage of the Boron element B cannot be determined, although its presence can be confirmed. The chemical composition of the coatings was analysed by Energy-Dispersive X-ray spectroscopy (EDS).

\subsection{Wear tests}

Two different wear tests were conducted as part of this work in Belgian Ceramic Research Centre (Mons, Belgium). It is important to note that these tests are carried out without any lubrication to study the wear behaviour under severe conditions. In addition, all samples have been polished and properly cleaned before performing the tests. In the dry sand/wheel test, the test specimen is pressed against the rotating wheel at a specified force by means of a lever arm while a controlled flow of grid abrades the test surface. The rotation of the wheel is such that its contact face moves in the direction of the sand flow [19]. Figure 1 shows the sand/wheel wear test set-up. The test was carried out at room temperature (about $20^{\circ} \mathrm{C}$ ) under a load of $30 \mathrm{~N}$ for a constant duration of $16 \mathrm{~min}$ for each test, which corresponds to 20000 revolutions at constant wheel rotation speed $(1250 \mathrm{t} / \mathrm{min})$. The flow rate of abrasive particles $\left(\mathrm{Al}_{2} \mathrm{O}_{3}\right)$ was between 300 and $400 \mathrm{~g} / \mathrm{min}$. The volume loss of coating material that presents the resistance to wear was calculated theoretically from the length of the wear track measured after the test using a 3D digital microscope. Ten profiles of the wear track being made, from the first edge of the wear track to the second, and then calculate an average value of the wear track length. The worn volume is calculated according to the formula [18]:

$$
\begin{gathered}
V=\left(\frac{\pi \cdot \alpha}{180}-\sin \alpha\right) \frac{h d^{2}}{8} \\
\sin (0,5 \alpha)=\frac{L}{d}
\end{gathered}
$$

where $\mathrm{V}$ is the volume loss $\left[\mathrm{mm}^{3}\right], \mathrm{h}$ is the thickness of rotating disc $[\mathrm{mm}](10 \mathrm{~mm}), \mathrm{d}$ is the diameter of rotation disc $[\mathrm{mm}], \alpha$ is the angle in degrees and $\mathrm{L}$ is the impression length measured [mm]. 


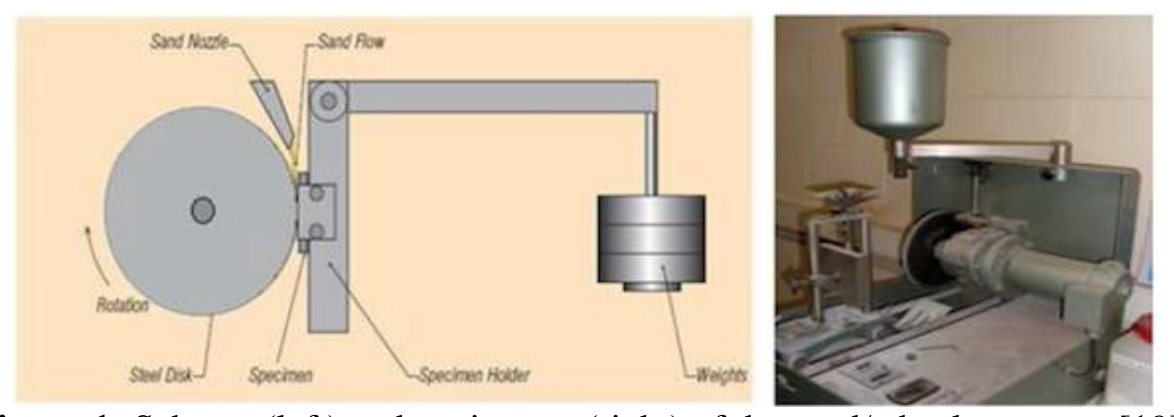

Figure 1: Schema (left) and equipment (right) of the sand/wheel wear test [19].

The pin-on-disc test is a method for analysing a material wear and the friction coefficient between two materials. In this work, a pin-on-disc tribometer (Figure 2) was used under a normal load of $10 \mathrm{~N}$, a sliding speed of $0.1 \mathrm{~m} / \mathrm{s}$ and using an alumina pin $\left(\mathrm{Al}_{2} \mathrm{O}_{3}\right)$ with a diameter of $8 \mathrm{~mm}$ [19]. The volume loss was calculated theoretically; it was not measured by profilometry given the amount of debris accumulated in the groove. The volume loss was therefore calculated from the width measurements of the grooves for each sample using 3D digital microscope.

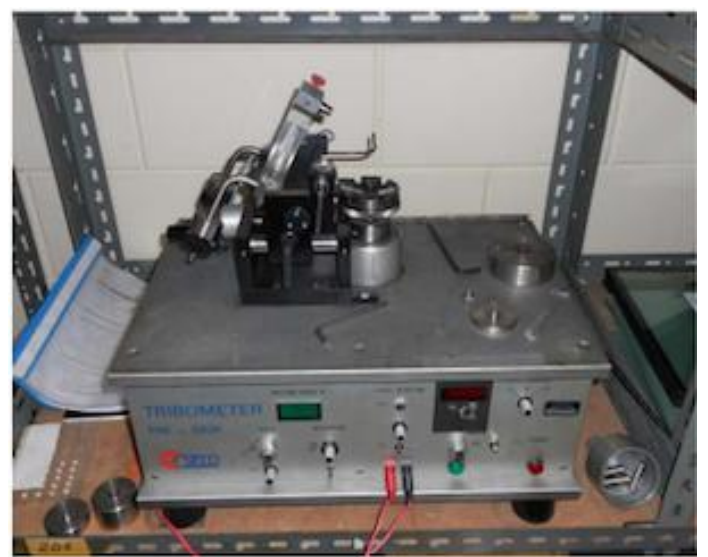

Figure 2: Equipment of pin-on-disc test (CRIBC) [19].

In the case of pin-on-disc test, we can estimate the volume of worn material by direct measurement observing the worn track. The formula used to calculate the worn volume is as follows [20]:

$$
V_{d i s c}=\frac{\pi \cdot r \cdot\left(S_{1}+S_{2}+S_{3}+S_{4}\right)}{2}
$$

where $V_{\text {disc }}$ is the wear volume of the disc $\left[\mathrm{mm}^{3}\right], \mathrm{r}$ is the wear track radius [mm], S1 to $\mathrm{S} 4$ are the wear track area taken at 4 different locations (as shown in Figure 3) $\left[\mathrm{mm}^{2}\right]$.

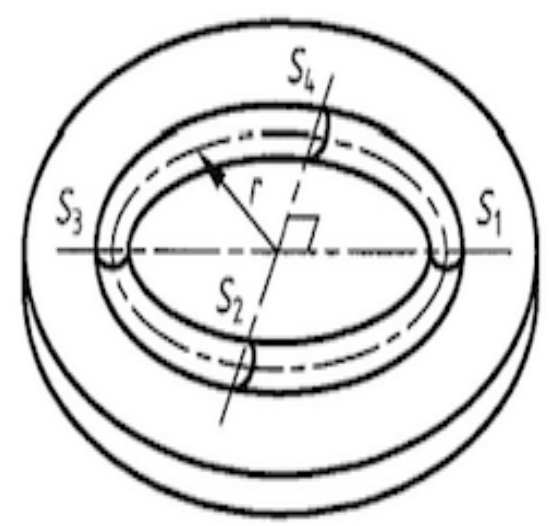

Figure 3: Circular wear track on the disc [20]. 
The specific wear rate of the disc is calculated based on the wear volume according to the formula given by the European Norm prEN 1017-13:2008 [20]:

$$
W_{s(\text { disc })}=\frac{V_{\text {disc }}}{F_{n} L}
$$

where $W_{s(\text { disc })}$ is the specific wear rate of the disc $\left[\mathrm{mm}^{2} / \mathrm{N}\right], F_{n}$ is the applied normal force $[\mathrm{N}]$ and $\mathrm{L}$ is the friction distance $[\mathrm{mm}]$.

Finally, the microstructure of the wear track for all samples was analysed by scanning electron microscopy to understand the wear mechanism.

\section{Results and discussion}

\subsection{Microstructure characterisation}

Figure 4 shows the micrograph of flame thermal sprayed NiCrBSi coating obtained by optical microscopy and SEM. Regarding the microstructure, it is clear that coating does not clearly reveal a lamellar structure as shown in literature relative to thermal spray coatings. As global view of coating cross section, the presence of certain level of porosity was observed but was not too pronounced. However, no cracking was observed. According to literature [21], impact temperature and velocity of particles, among other parameters, governing the spreading degree of the splats forming the deposit. Low particle velocity characteristic of flame thermal spraying process ensures that some particles are not well spread at the time of impact on the substrate and therefore, this phenomenon promotes the presence of porosity in coating. Figure 5 shows the micrograph of flame thermal sprayed $\mathrm{NiCrBSi}$ coating reinforced with tungsten carbide. As we can see, layer structure is modified by adding WC particles but remains homogeneous. The thermal sprayed composites are composed of matrix and a second phase known as reinforcement, which is WC in our study. WC particles are easily identifiable by their different color and angular shape; they have kept the same shape as in initial powder. Reinforced NiCrBSi coating has a similar level of porosity to that of single NiCrBSi coating with presence of microcracks in the matrix and tungsten carbide particles. These defects are typical of coatings produced by thermal spraying.

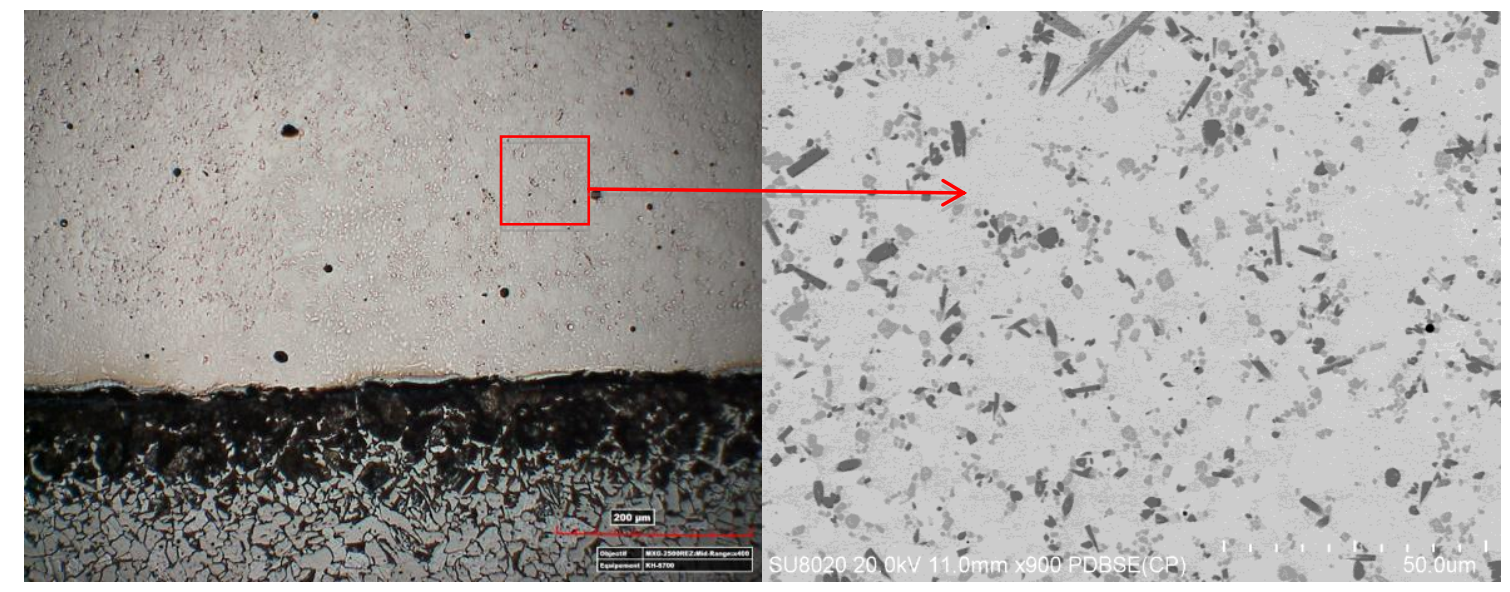

Figure 4: Micrograph of flame thermal sprayed NiCrBSi coating obtained by optical microscopy (left) and SEM (right).

The Ni-based matrix contains Nickel, Chromium, Iron, Silicon and Boron. Binary phase diagrams such as NiCr, $\mathrm{NiB}$, and $\mathrm{NiSi}$ provide information on the effects of individual alloying elements on the melting temperature of $\mathrm{NiCrBSi}$ alloy [22]. They show that the presence of $\mathrm{Cr}, \mathrm{Si}$ and $\mathrm{B}$ elements reduce the melting temperature point of nickel Furthermore, these three elements play a role in forming hard borides and carbides, owing to improve the mechanical properties of the produced coating. The NiCrBSi is made of a Ni-rich solid solution phase $\gamma-\mathrm{Ni}$ and low content of $\mathrm{Ni}_{-} \mathrm{Ni}_{3} \mathrm{~B}$ eutectic [7]. When the spraying alloy solidified from high temperature, several possible borides, carbides and silicates may be created, such as, $\mathrm{Ni}_{2} \mathrm{~B}, \mathrm{CrB}, \mathrm{Ni}_{5} \mathrm{Si}_{3}, \mathrm{Ni}_{13} \mathrm{Si}_{12}, \mathrm{Ni}_{3} \mathrm{Si},(\mathrm{Cr}, \mathrm{Fe})_{7} \mathrm{C}_{3}$ and $\mathrm{Cr}_{23} \mathrm{C}_{6}$. Which one is produced depends to a large extent on the composition of the alloy and the solidification process. Based on the XRD analyses, the NiCrBSi coating was mainly composed by $\gamma-\mathrm{Ni}, \mathrm{CrB}$ and $\mathrm{Ni}_{3} \mathrm{~B}$ phases. With regard to the XRD results and the microstructure of $\mathrm{NiCrBSi}$ coating, the dark grayphase is chromium boride $\mathrm{CrB}$, while the light phases can be identified as the $\gamma$-Ni solution and $\mathrm{Ni}_{3} \mathrm{~B}$. The XRD 
analysis of the composite coating confirms the presence of $\mathrm{WC}, \gamma-\mathrm{Ni}$ solid solution and a small amount of $\mathrm{Ni}_{3} \mathrm{~B}$ phase in the coating. Other precipitates such as $\mathrm{W}_{2} \mathrm{C}$ and $\mathrm{Cr}_{7} \mathrm{C}_{3}$ were found in the $\mathrm{WC}$ composite coating matrix. These phase compositions are in accord with those reported in literature.

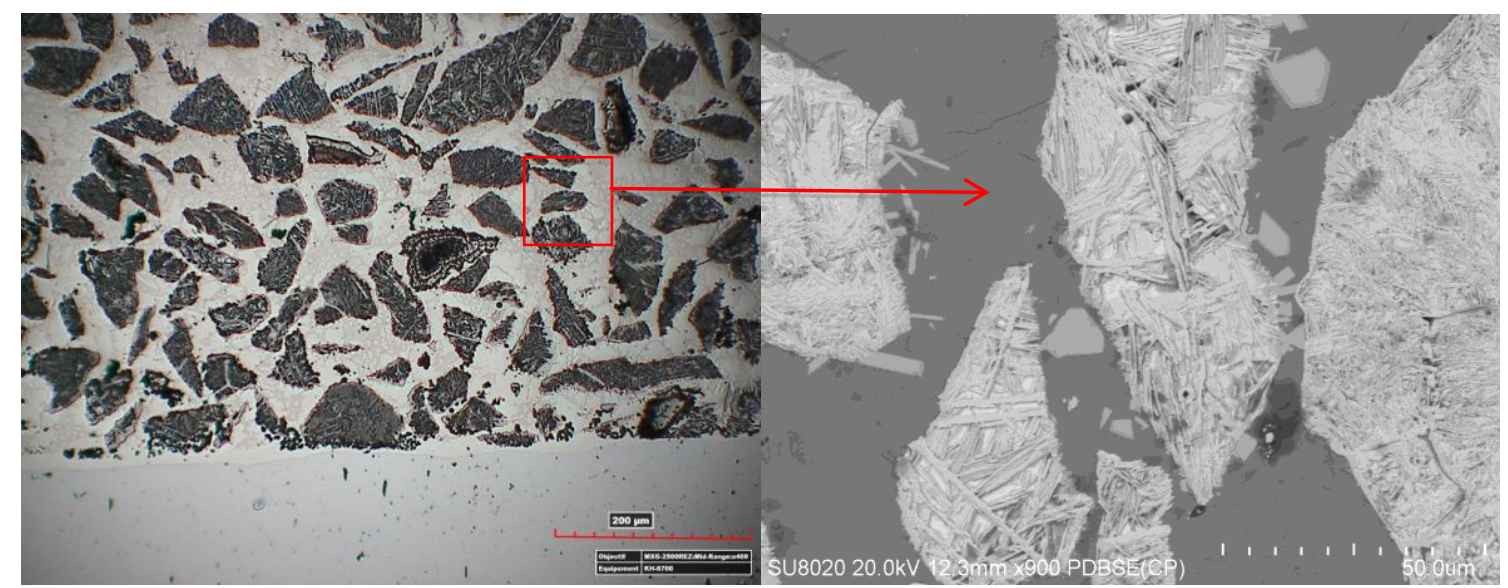

Figure 5: Micrograph of flame thermal sprayed NiCrBSi coating reinforced with WC, obtained by optical microscopy (left) and SEM (right).

Adding hard particles to the matrix can increase the hardness of the coating. Microhardness tests were performed onto mild steel substrate and coatings layers and the measurements were carried out in Vickers microhardness under a load of $300 \mathrm{gf}$. The results show that the average microhardness of NiCrBSi coating (820 $\left.\mathrm{HV}_{0.3}\right)$ is much higher than those reported in the literature (about $\left.610 \mathrm{HV}_{0.3}\right)$. The reason may be the cohesion of coating as well as the formation of small precipitates like chromium borides and carbides, which are distributed in the microstructure [14]. NiCrBSi-60\%WC layers are the hardest ones on the surface. Indeed, the presence of WC hard ceramic particles in the coating lead to an increase in the microhardness value. From the interface steel/ coating, NiCrBSi coating has a uniform hardness around $800 \mathrm{HV}_{0.3}$ with uniform behaviour. NiCrBSi$60 \%$ WC coating shows a significantly higher hardness $\left(1200 \mathrm{HV}_{0.3}\right)$, but with significant variations from one point to another, which can be attributed to the WC particles agglomerate in the Ni-based matrix. In the presence of $\mathrm{NiCrBSi}$ and $\mathrm{NiCrBSi}-60 \% \mathrm{WC}$ coating, hardness is significantly higher compared to that of the steel substrate. Cracks present in the NiCrBSi-60\%WC coating can be justified by its high hardness and low fracture toughness.

\subsection{Dry Sand/Wheel erosive wear test}

Figure 6 illustrates the results of the wear resistance achieved with the sand/wheel test (after 20000 revolutions of the wheel). This result is the evolution of the material loss volume during the test depending on studied materials (at room temperature).

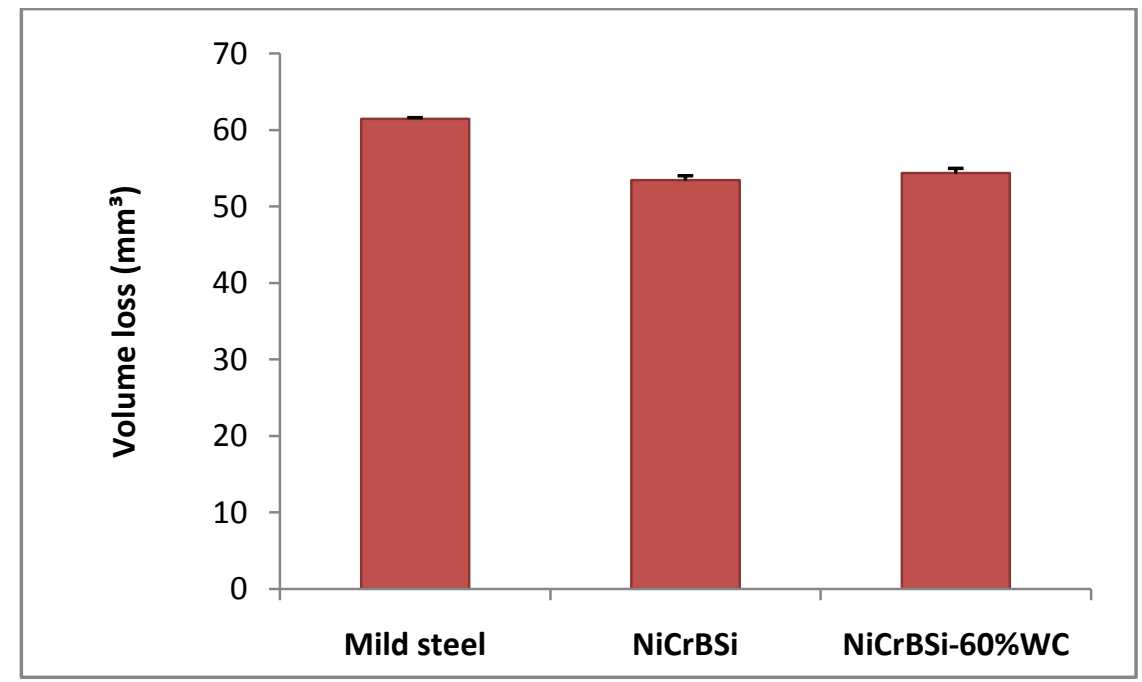

Figure 6: Results of sand/wheel wear test for different used materials. 
From these results, the following conclusions can be provided:

- The wear resistance is improved thanks to NiCrBSi layer. The lost material volume has been decreasing by $61 \mathrm{~mm}^{3}$ for the steel substrate to $53 \mathrm{~mm}^{3}$ for the metal matrix.

- The best abrasive wear resistance is that shown by the metal matrix. Unusually, the composite layer made from the powder with $40 \% \mathrm{NiCrBSi}-60 \% \mathrm{WC}$ revealed lower wear-resistance than the NiCrBSi matrix.

\subsection{Pin-on-disc wear test in continuous motion}

The pin-on-disc test in continuous motion has been made at room temperature. Wear volumes were then calculated using the model mentioned above. In Figure 7 is shown the volume loss evolution of coating material during the test with the alumina pin, depending on each material. It is clear that the wear rate is widely decreased with the application of coating. The Nickel alloy sample has wear rate less than that of the reinforced Nickel alloy, but remains generally close to that of Nickel alloy. This result is unexpected because, according to the literature, the addition of WC particles should increase the wear resistance.

The results show that the behaviour obtained by pin-on-disc test (abrasive wear) of the three materials (mild steel, NiCrBSi, NiCrBSi-60\%WC) is similar to the behaviour obtained by sand/wheel test (erosive wear).

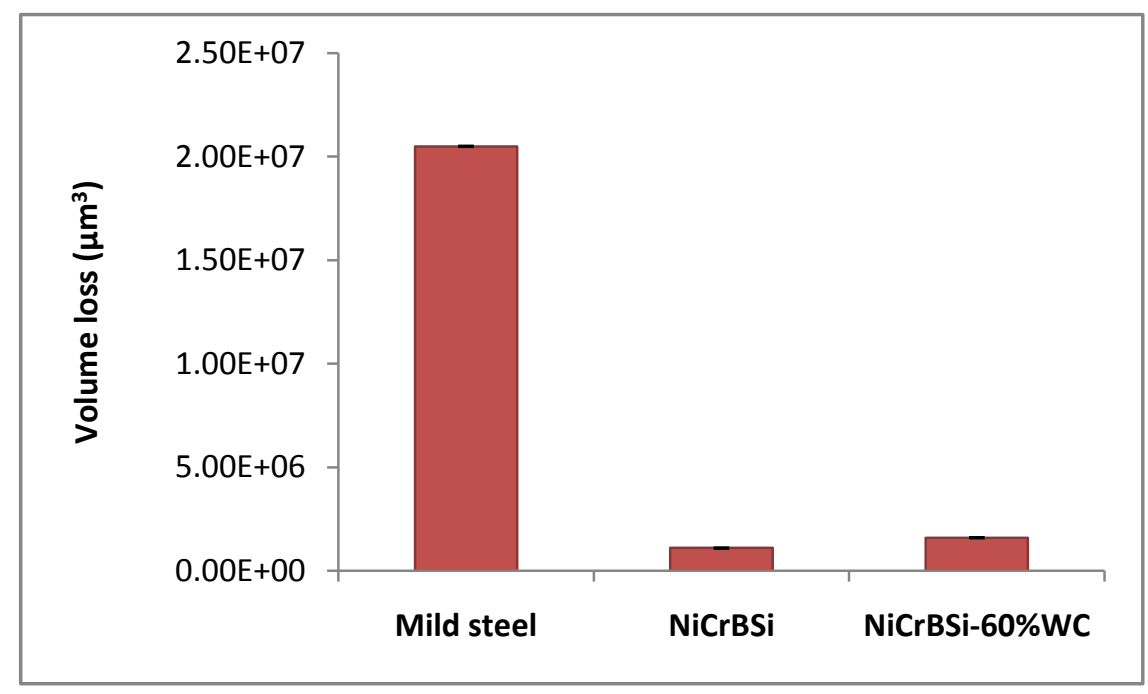

Figure 7: Results of pin-on-disc wear test for different materials.

\subsection{Wear mechanisms}

The use of a high WC content (60\%-wt.) increases the level of internal stresses of the layers and thus the risk of cracking during shocks with WC particles, which cause a decrease in the wear resistance. Therefore, one explanation could be linked to the residual defects like cracks in the composite coating due to the presence of ceramic particles, and porosity defects, which may be due to the operating mode when making deposits. Many authors have proposed different solutions to reduce cracks and porosity level in coatings, such as optimizing operating parameters [23], post-heat treatment [24], etc.

This behaviour can be also justified by the detachment of WC particles during the test and can be confirmed by SEM observation of wear track on the reinforced sample (Figure 10). Indeed, the faceted shape of the WC particles enables its geometric boundaries to be defined, and it may be that the connection with the matrix is not too good or has been weakened by the removal of the metal matrix material during test, which promotes the sample detachment more easily. Consequently, an increase in the wear rate is observed. Some similar results have been reported in literature work [6]. Martin et al. [1] suggested that the wear rate of the coating should be considered together with the mass loss rate of the counterbody. At room temperature, the sample is in severe contact with the alumina pin, but as the temperature increases, some particles of the Nickel alloy are transferred to the counterbody, thereby developing a soft layer and reducing the severity of the contact. The abrasiveness of the ceramic WC particles prevents the transfer of material between the sample and the counterbody and therefore the severity of the contact is little changed as the temperature increases. This material transfer of the metal matrix to the pin surface may be the mechanism responsible for the decrease in the volume loss for the 
NiCrBSisample. However, this mechanism was not confirmed by SEM observation of wear track on the counterbody. Another wear mechanism encountered in literature is the plastic deformation [25].

Furthermore, the counterbody material $\left(\mathrm{Al}_{2} \mathrm{O}_{3}\right)$ can be transferred to the coating surface [9], which is confirmed by the SEM observation of the wear tracks as shown in Figure 11.

For this purpose, the grooves were analysed by digital microscopy to determine the volume loss of coating material. During the test, no process has been applied to evacuate the debris that occurring. In contrast, at the end of the test, it is possible that the debris is evacuated at the periphery of the groove as they can be transferred at the friction surface of the counter body. Figure 8 shows the pin's faces and the wear profile of corresponding material after test.

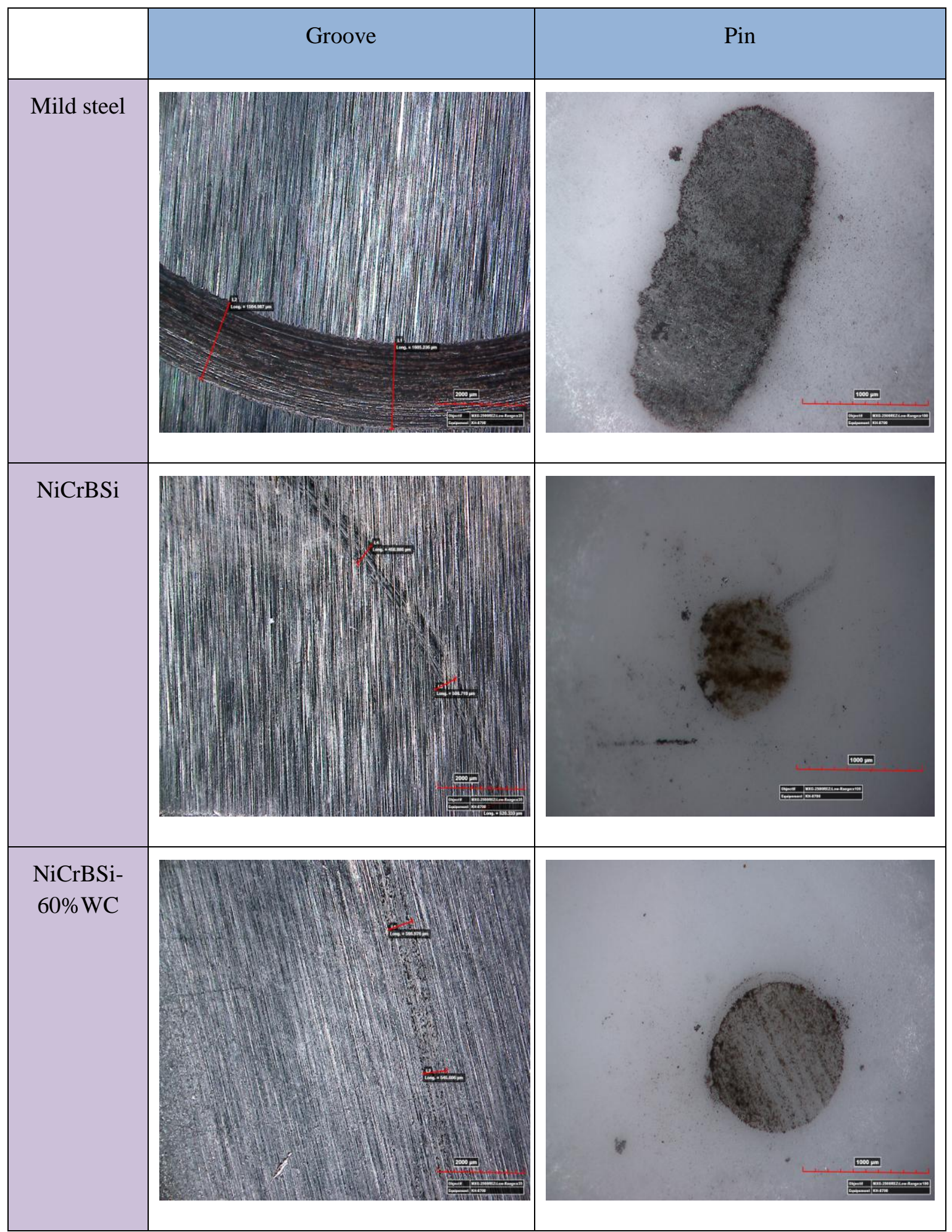

Figure 8: Analysis of wear track for the pin and the different materials after pin-on-disc test. 
The grooves are formed by many wear track oriented in the wheel's direction of rotation (Figure 9). The same phenomenon is observed for wear track in the case of the sand/wheel test. Observing the wear track on the pin in the case of reinforced coating, it can be noticed that it is greater than in the case of NiCrBSi sample. This may be due to the presence of big content of tungsten carbide particles within the NiCrBSi-60\%WC powder, which considerably increases the loss of pin material during testing, while no improvement is observed about the wear resistance of the reinforced coating layer. As indicated in literature review, the concentration of WC plays an important role about the wear resistance. Probably, that the studied concentration of reinforcing particles in this work does not promote the wear resistance of the tested samples.
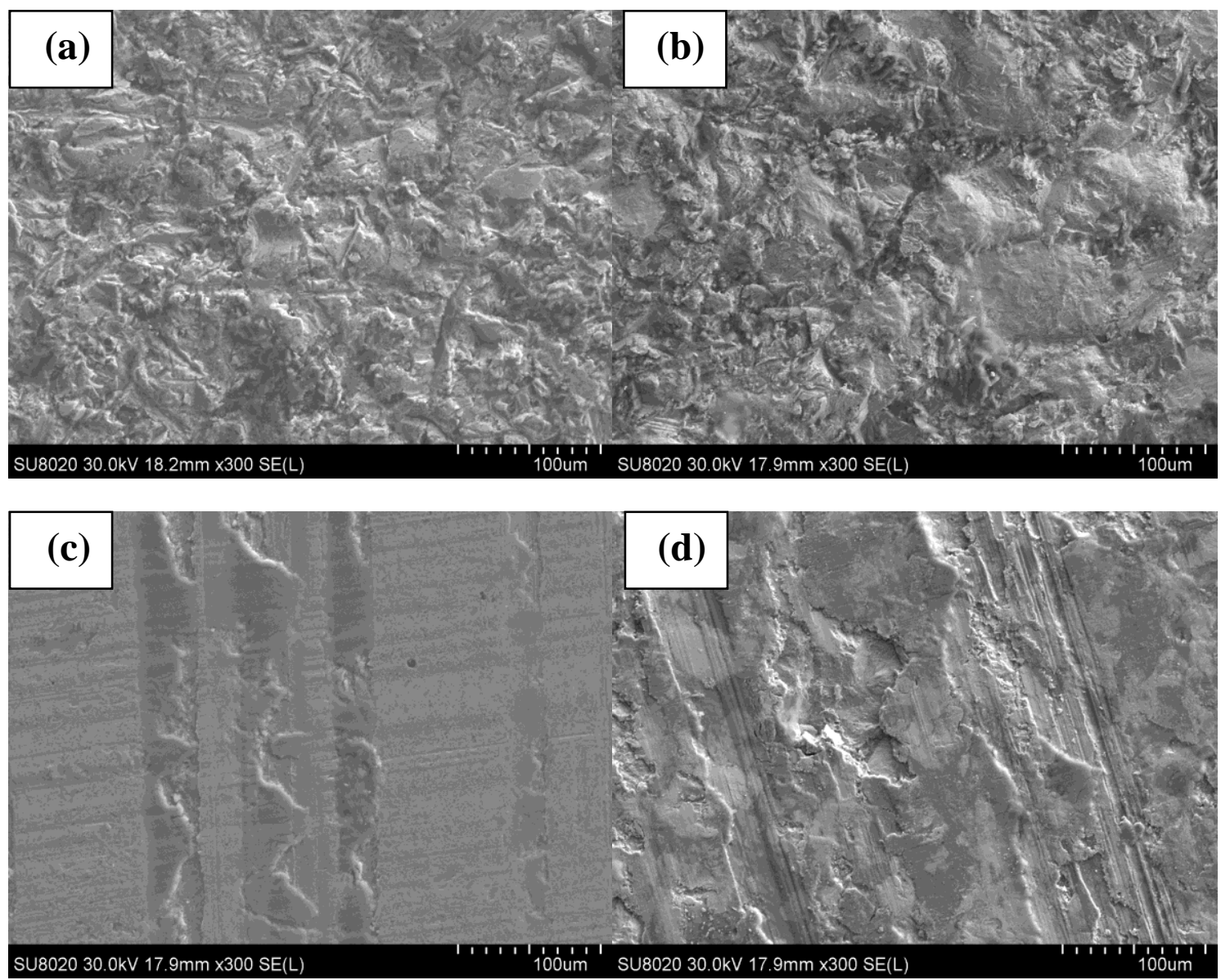

Figure 9: SEM micrographs of worn surface after Sand/Wheel test: (a) NiCrBSi, (b) WC reinforced NiCrBSi and after pin-on-disk test: (c) NiCrBSi, (d) WC reinforced NiCrBSi.

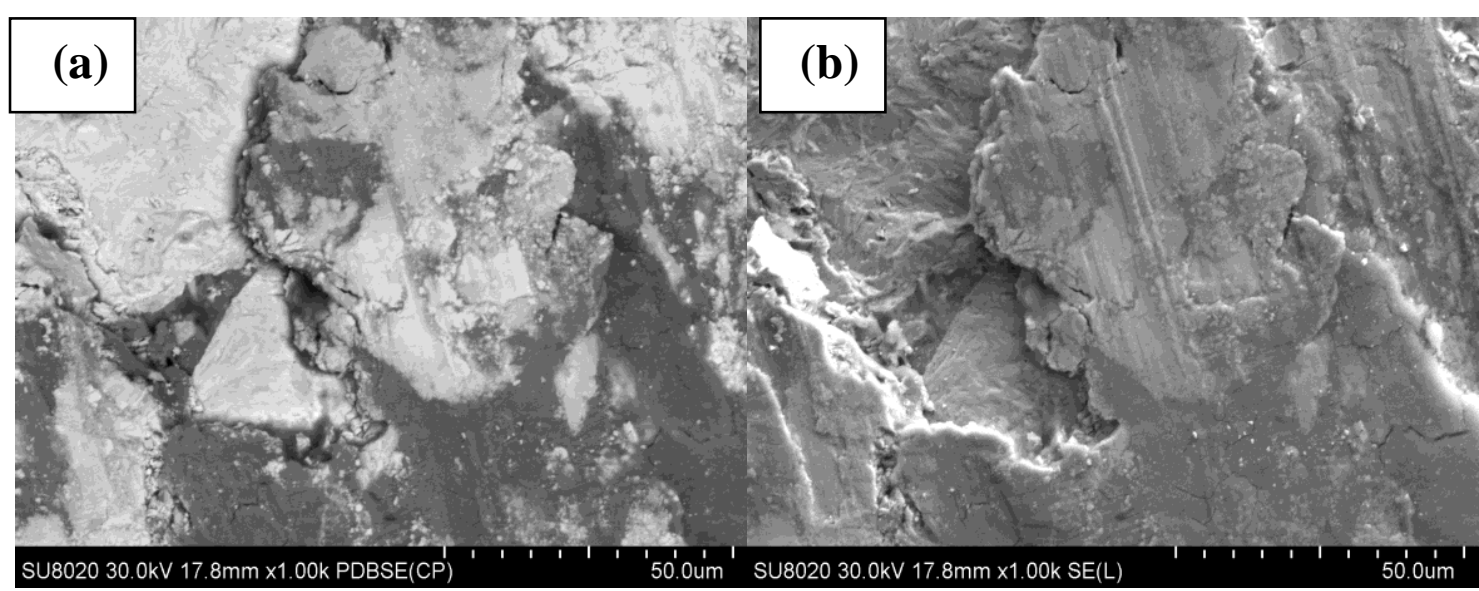

Figure 10: SEM images showed the detachment of WC particles during the pin-on-disc test: (a) SEM-backscattered electrons and (b) SEM-secondary electrons 

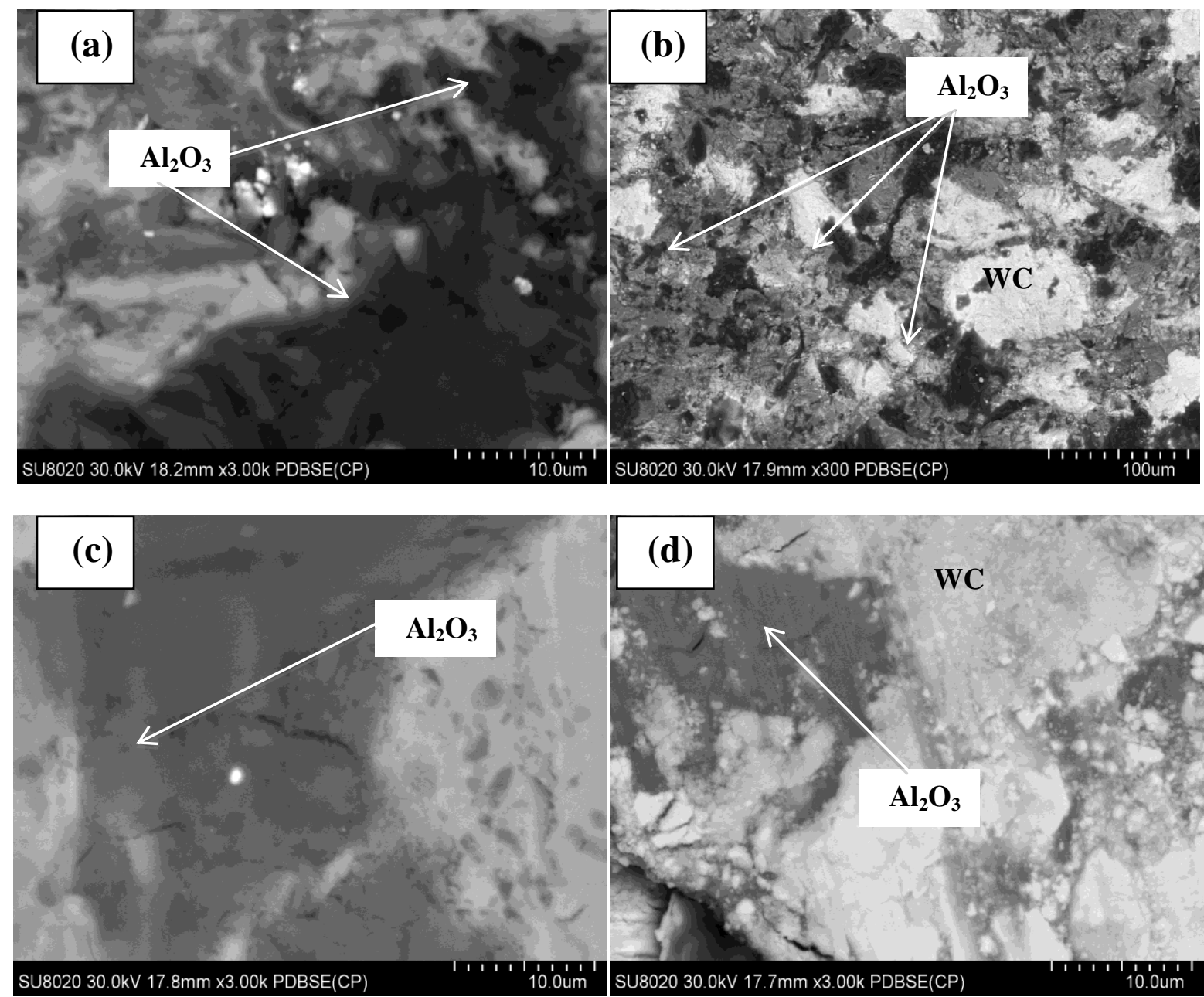

Figure 11: $\mathrm{SEM}$ images showed the transfer of $\mathrm{Al}_{2} \mathrm{O}_{3}$ material from the pin to coating surface: (a) NiCrBSi and (b) WC reinforced for the Sand/Wheel test, (c) NiCrBSi and (d) WC reinforced NiCrBSi for the pin-on-disk test

\section{Conclusions}

In this paper, the effects of adding WC reinforcing ceramic phase on the microstructure and wear resistance of the coatings have been investigated. For the wear tests, it was concluded that:

- Coating microstructure plays an important role on its wear resistance.

- To effectively judge the wear resistance of coating layer, we must not only consider the hardness which, while being an important parameter, but still insufficient (taking into account other parameters such as toughness). A harder material is not necessarily a better wear resistance, at least for the two wear tests used in this study.

- Tungsten carbide particles plays the role of an abrasive which considerably increases the counter-body wear rate (alumina counter), but the wear rate remains close to that of the unreinforced Ni-based alloy.

- Wear mechanism is mainly controlled by the scratching and by the pull out of WC particles because of their faceted shape.

- The concentration of WC has an influence on the hardness and wear resistance, hence the need to extend the study on different WC concentrations.

Acknowledgments The authors wish to thank the ARES-CCD development cooperation and CNRST for the financial support, and Materia Nova Centre (Mons, Belgium) for the SEM analysis. 


\section{References}

1. Martin A., Rodríguez J., Fernández J. E., Vijande R., Wear, 251 (2001) 1017-1022.

2. Maatta A., Kanerva U., Vuoristo P., Therm. Surf. Technol, 20 (2011) 366-371.

3. Lima R. S., Moreau C., Marple B. R., Therm. Surf. Technol., 16 (2007) 866-872.

4. Houdkova S., Zahalka F., Kasparova M., Berger L. M., Tribol. Lett., 43 (2011) 139-154.

5. Navas R. C. C., de Damborenea J., Vitar R., Surf. Coat. Technol, 200 (2006) 6854-6862.

6. Zikin A., Antonov M., Hussainova I., Katona L., Gavrilovic A., Tribol. Int, 68 (2013) 45-55.

7. Kim H. J., Hwang S. Y., Lee C. H., Juvanon Ph., Tribol. Lett., 172 (2003) 262-269.

8. Higuera Garrrido A., Gonzalez R., Cadenas M., Hernandez Battez A., Wear, 271 (2011) 925-933.

9. Miguel J. M., Guilemany J. M., Vizcaino S., Tribol. Int, 36 (2003) 181-187.

10. Godwin G., Julyes Jaisingh S., Shunmuga Priyan M., Mater. Sci. Surf. Eng., 5 (2017) 537-543.

11. Axén N., Hogmark S., Jacobson S., CRC Press LLC, 13 (2001).

12. Huang S. W., Samandi M., Brandt M., Wear, 256 (2004) 1095-1105.

13. Rodríguez J., Martin A., Fernández R., Fernández J. E., Wear, 255 (2003) 950-955.

14. Reinaldo P. R., Oliveira A. S. C. M. D., Mater. Eng. Perform, 22 (2013) 590-597.

15. Lu S. P., Kwon O. Y., Guo Y., Wear, 254 (2003) 421-428.

16. Grewal H. S., Singh H., Agrawal A., Wear, 301 (2013) 424-433.

17. Paul C. P., Mishra S. K., Tiwari P., Kukreja L. M., Opt. Laser Technol., 50 (2013) 155-162.

18. Norme ASTM G65-04, Standard test method of measuring a brasión using the dry Sand/Rubber Wheel apparatus (2004).

19. Deschuyteneer D., Petit F., PhD Thesis, BCRC Belgium (2014).

20. Norme Européenne prEN 1071-13, Advanced technical ceramics-method test for ceramic coatings- Part 13: Determination of wear rate by the pin-on-disk method (2008).

21. Mostaghimi J., Pasandideh-Fard M., Chandra S., Plasma Chem. Plasma Process, 22 (2002) 59-84.

22. Okamoto H., Schlesinger M., Mueller E., Alloy Phase Diagrams, ASM Handbook, ASM International, 3 (2003) 432, 692,1233.

23. Molak R. M., Araki H., Watanabe M., Katanoda H., Ohno N., Kuroda S., Therm. Spray Tech., 26 (2017) 627-647.

24. Li G. J., Li J., Luo X., Opt. Laser Technol., 65 (2015) 66-75.

25. Garrido M. A., Rico A., Gómez M. T., Cadenas M., Fernández-Rico J. E., Rodríguez J., Therm. Spray Tech., 26 (2017) 517-529.

(2017) ; http://www.jmaterenvironsci.com 